\title{
The Effect of $N$-nitrosodimethylamine (NDMA) on Bax and Mcl-1 Expression in Human Neutrophils
}

\author{
Jakub Jablonski • Ewa Jablonska • Agnieszka Leonik
}

Received: 28 September 2010/ Accepted: 2 September 2011/Published online: 27 September 2011

(c) The Author(s) 2011. This article is published with open access at Springerlink.com

\begin{abstract}
In the present study we examined a role of proapoptotic Bax and anti-apoptotic Mcl-1 proteins, participating in the regulation of intrinsic apoptosis pathway in human neutrophils (PMNs) exposed to $N$-nitrosodimethylamine (NDMA), the environmental xenobiotic. For the purpose comparison, the same studies were conducted in autologous peripheral blood mononuclear cells (PBMCs). The production of cytochrome $\mathrm{c}$ by PMNs was also determined. A deficit of anti-apoptotic Mcl-1 and overexpression of the pro-apoptotic protein Bax suggest that the apoptosis process in human neutrophils exposed to NDMA is dependent on changes in the expression of these proteins. PMNs were more sensitive to NDMA than PBMCs.
\end{abstract}

Keywords Apoptosis - Neutrophils - Mononuclear cells · $N$-nitrosodimethylamine

$N$-nitrosodimethylamine (NDMA) belonging to xenobiotics is a carcinogenic compound present in processed food, tobacco smoke or beer (Lijinsky 1999). The toxic effect of NDMA, similarly to many other xenobiotics, reveals a great influence on the biological activity of the immune cells (Drela 2006).

Our previous in vitro studies demonstrated the influence of NDMA on oxygen metabolism in human neutrophils (PMNs), the cells which play a significant role in

J. Jablonski ( $\square)$

Department of Toxicology, Medical University of Bialystok,

Mickiewicza 2c, 15-222 Bialystok, Poland

e-mail: toksykologia@wp.pl

E. Jablonska · A. Leonik

Department of Immunology, Medical University of Bialystok,

Waszyngtona 15a, 15-269 Bialystok, Poland antibacterial, antifungal and antitumor defense mechanisms (Jablonski et al. 2003). Furthermore, the results of our examinations also suggested that NDMA may limit the lifespan of neutrophils. We have found that NDMA, through the induction of a respiratory burst and subsequent release of reactive oxygen species (ROS), is responsible for the apoptosis of these cells (Jablonski et al. 2001).

Data are available confirming the important role for ROS in neutrophil apoptosis pathways (Simon 2003; Lee et al. 2002). Lee et al. showed the involvement of ROSactivating p38 MAP kinase in tumor necrosis factor (TNF)_related apoptosis-inducing ligand (TRAIL) induced apoptosis (Lee et al. 2002).

TRAIL and its specific cell "death receptors" TRAILR1 (DR4) and TRAIL-R2 (DR5) belong to the TNF family of proteins, and have been shown to directly induce the extrinsic cell signaling pathway of apoptosis (Sprick and Walczak 2004; Simon 2003). Upon binding TRAIL, DR4 and DR5 recruit and activate the extrinsic pathway of apoptosis-initiating the proteases caspase- 8 and caspase10 via the adaptor protein called Fas with death domain (FADD). Caspase-8 and-10 activate effector caspase-3, -6 and -7 leading to degradation of intracellular substrates and cell death (Clohessy et al. 2006). The data presented by Renshow et al. indicated that DR5 rather than DR4 is a death-inducing TRAIL receptor in neutrophils (Renshaw et al. 2003).

Results obtained in our laboratory suggest that NDMA can modulate the apoptosis of human neutrophils by influencing the expression of death receptor DR5 as well as through the release of its soluble form (sDR5) (Jablonski and Jablonska 2007).

The mechanism of NDMA activity on the induction of apoptosis can be multifactorial. In the evaluation of the mechanisms of the NDMA-induced apoptosis, the influence 
of this compound on the expression of the $\mathrm{Bcl}-2$ gene seems to be of importance (Lee 1997). Bcl-2 protein belongs to the Bcl-2 family proteins participating in the regulation of the intrinsic apoptosis pathway (Simon 2003; Edwards et al. 2004)

The intrinsic pathway is activated by mitochondrial disruption with subsequent release of mitochondrial apoptogenic factors such as cytochrome c, Smac/DIABLO and Omi/HtrA2 (Sharpe et al. 2004). It is known that neutrophils constitutively express the pro-apoptotic Bcl-2 family members such as Bax, as well as anti-apoptotic proteins such as Mcl-1. It is important to note that the mitochondrial signaling pathway plays a significant role in the apoptosis of human neutrophils (Edwards et al. 2004).

The key question of this study was whether the proteins of the Bcl-2 family, pro-apoptotic Bax and anti-apoptotic Mcl-1, participate in the NDMA-induced apoptosis of human neutrophils. Additionally, to explain a possible role of pro-apoptotic protein Bax in this process, we examined the concentration of cytochrome $\mathrm{c}$, the secretion of which is initiated by this protein.

Since NDMA depresses the response of mononuclear immune cells, the mechanistic process of which remains unclear (Holsapple et al. 1985), we also estimated the expression of Bax and Mcl-1 proteins in autologous peripheral blood mononuclear cells (PBMCs). The research may contribute to our understanding of the mechanisms that impair leukocyte function in persons exposed to NDMA.

\section{Materials and Methods}

Preparation of PMNs and PBMCs: 10 healthy donors aged 22-50 (mean age: 36) were examined. Cells were isolated from whole blood treated with EDTA by density centrifugation using Polymorphoprep (Axis-Shield, Oslo, Norway) (density-1.113 g/mL) (Bøyum 1976). This method enables simultaneous separation of two highly purified leukocyte fractions: mononuclear cells (PBMCs) and polymorphonuclear neutrophils (PMNs). The purity of isolated PMNs and PBMCs was determined by May-GrunewaldGiemsa-staining.

Culture of PMNs and PBMCs: The cells were suspended in the culture medium RPMI-1640 (Biomed, Lublin, Poland) to provide $5 \times 10^{6}$ cells $/ \mathrm{mL}$ and were incubated in flatbottomed 96-well plates (Microtest III-Falcon, Franklin Lakes, USA) for $20 \mathrm{~h}$ at $37^{\circ} \mathrm{C}$ in a humidified incubator with $5 \% \mathrm{CO}_{2}\left(\mathrm{NUAIRE}^{\mathrm{TN}}\right)$. PMNs and PBMCs were treated with NDMA (Sigma-Aldrich, Steinheim, Germany), at concentrations of 1 and $5 \mathrm{mg} / \mathrm{mL}$. The viability of PMNs and PBMCs measured after incubation was $94 \%$ and $96 \%$, respectively.
Western blot analysis: Cytoplasmic protein fractions of PMNs and PBMCs were analyzed with the use of western blotting for the presence of Bax and Mcl-1. Cells were lysed directly in the presence of Protease Inhibitor Coctail (Sigma-Aldrich, CHEME GmbH P.P. Steinheim, Germany) by sonication using Vibra-Cell Ultrasonic Processor (Sonics\&Materials, Inc., USA). Protein fractions were suspended in Laemmli buffer (Bio-Rad Laboratories, Herkules CA, USA) and then separated by electrophoresis on SDS-PAGE. The resolved protein was transferred onto $0.2 \mu \mathrm{m}$ pore-sized nitrocellulose (Bio-Rad Laboratories, Herkules CA, USA). The nitrocellulose was incubated at $+4^{\circ} \mathrm{C}$ for $20 \mathrm{~h}$ with the primary monoclonal antibody antiBax or anti-Mcl-1 (Alexis, Carlsbad CA, USA). After washing with $0.1 \%$ TBS-T [containing: $10 \times$ Tris-Buffered Saline (Bio-Rad Laboratories, Herkules CA, USA) and Tween 20], the membrane was incubated at room temperature for $1 \mathrm{~h}$ with alkaline phosphatase anti-mouse IgG Abs (1:200; Vector Laboratories, Burlingame, CA, USA). Immunoreactive protein bands were visualized following the addition of AP-Conjugate Substrate Kit (Bio-Rad Laboratories, Herkules CA, USA) with Rusing IMAGEJ (public domain, Java-based image processing program developer at the National Institutes of Health, USA) software and estimated by arbitrary units.

Apoptosis evaluation: Annexin V binding of neutrophils was performed using an apoptosis detection kit (APOTEST ${ }^{\mathrm{TM}}$ _FITC, Nexins Research, Holland) according to manufacturer's instructions. Briefly, $10^{5}$ cells/ $\mathrm{mL}$ freshly isolated cells or incubated cells were labeled with FITC-conjugated annexin $\mathrm{V}$ and propidium iodide (PI) for $20 \mathrm{~min}$ at $+4^{\circ} \mathrm{C}$. The samples were analyzed by two-color flow cytometry using Cell Quest Analysis software (Becton-Dickinson, Epics Coulter, USA). Results were reported in the form of the percentage of annexin $\mathrm{V}$-positive cells, which reflects the relative proportion of apoptotic cells in the early and late stages of apoptosis. If a cell is undergoing necrosis, annexin V- and PI-positive cells would be expected, whereas the presence of FITC-annexin V-positive but PI-negative cells is indicative of apoptotic rather than necrotic cell death.

Cytochrome c concentrations in PMNs lysates: PMNs were isolated from peripheral blood and incubated with NDMA $(5 \mathrm{mg} / \mathrm{mL})$. Cytochrome $\mathrm{c}$ concentrations in extracts of cells were measured by using Quantikine Cytochrome c Immunoassay (R\&D Systems, Minneapolis, USA) according to manufacturer' instruction. This assay recognizes natural human cytochrome c. A monoclonal antibody specific for cytochrome $\mathrm{c}$ has been pre-coated onto a microplate. The Standard supplied with this kit contains $40 \mathrm{ng}$ of cytochrome c from human placentas.

Data analysis: statistical analysis was performed with a statistics package Statistica 8.0 software (Statsoft, Cracow, 
Poland). The non parametric $U$ Mann-Whitney and Wilcoxon tests were used. Results were expressed as median \pm maximum and minimum values. The $p$ values smaller than 0.05 were considered statistically significant.

\section{Results and Discussion}

The survival of neutrophils regulated by the apoptosis process is determined by the balance between the expression of the pro-apoptotic and anti-apoptotic proteins (Simon 2003). Under in vitro conditions, regulators of intrinsic apoptosis pathway can be modulated by a variety of molecules, involving xenobiotics, such as NDMA.

In the present study, we found changes in the expression of pro-apoptotic Bax and anti-apoptotic Mcl-1 proteins in human neutrophils exposed to NDMA at a concentration of $5 \mathrm{mg} / \mathrm{mL}$. Bax expression was enhanced compared to controls and cells exposed to NDMA at $1 \mathrm{mg} / \mathrm{mL}$ (Fig. 1). In contrast, Mcl-1 expression in cells exposed to $5 \mathrm{mg} / \mathrm{mL}$ NDMA decreased in comparison to PMNs incubated without or in the presence of $1 \mathrm{mg} / \mathrm{mL}$ NDMA (Fig. 2). It is interesting to note that there were no differences in the presence of Bax and Mcl-1 proteins between control PBMCs and PBMCs exposed to NDMA at $5 \mathrm{mg} / \mathrm{mL}$ (Figs. 1, 2).

The increased expression of Bax and accompanying decreased expression of Mcl-1 may be responsible to a great extent from the accelerated apoptosis rates in neutrophils demonstrated in the study (Table 1). A statistically significant increase in the percentage of apoptotic PMNs was found during $20 \mathrm{~h}$ of incubation in the presence of $5 \mathrm{mg} / \mathrm{mL}$ NDMA, as compared to controls and cells exposed to $1 \mathrm{mg} / \mathrm{mL}$ NDMA.

The shortened lifespan of neutrophils limits their biological availability, leading to a decreased response to the different exogenous and endogenous pathogens. It was confirmed that apoptotic neutrophils are non-functional and lose certain abilities, such as movement by chemotaxis, generation of reactive oxygen species and degranulation (Akgul et al. 2001).

The deficit of Mcl-1 in neutrophils exposed to NDMA appears to have particular implications for the lifespan of these cells. The biological properties of Mcl-1 make it an important molecule responsible for acute and dynamic regulation of kinetic apoptosis (Edwards et al. 2004). Additionally, insufficient amounts of Mcl-1 generate free tBid and Bim, which are involved in the apoptotic events responsible for the increased intensity of apoptosis (Clohessy et al. 2006).

Overexpression of pro-apoptotic Bax in PMNs exposed to NDMA may enhance cytochrome c release from mitochondria (Sharpe et al. 2004). The observed in the

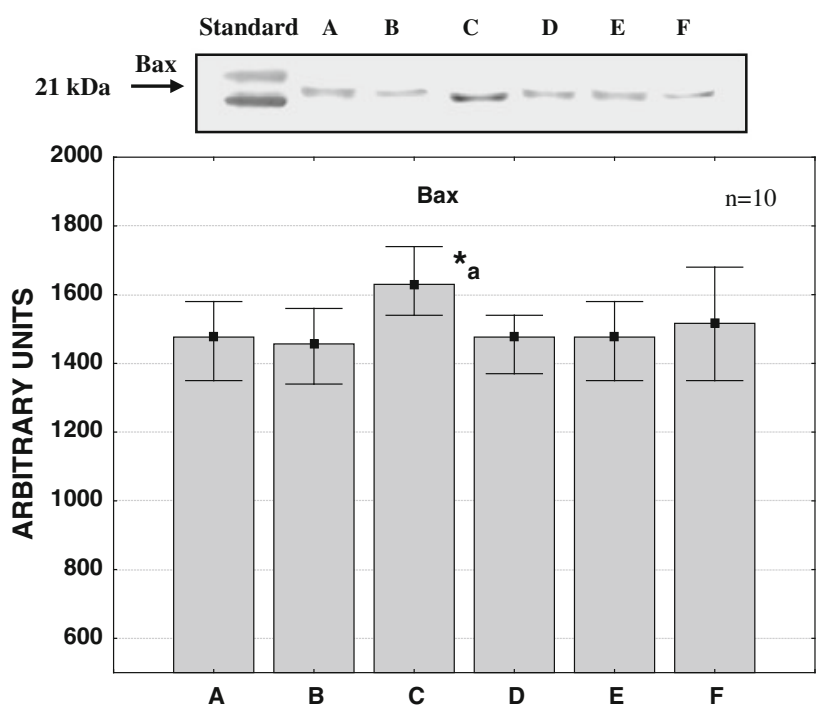

Fig. 1 Western blot analysis of Bax protein expression in human PMNs and PBMCs. A PMNs not exposed to NDMA (control), $B$ PMNs exposed to NDMA ( $1 \mathrm{mg} / \mathrm{mL}), C$ PMNs exposed to NDMA $(5 \mathrm{mg} / \mathrm{mL}$ ), $D$ PBMCs not exposed to NDMA (control), $E$ PBMCs exposed to NDMA (1 mg/mL), $F$ PBMCs exposed to NDMA $(5 \mathrm{mg} /$ $\mathrm{mL}$ ). Each value represents the median $\pm \min / \max$, for $\mathrm{n}=10$.

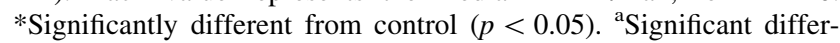
ence between cells exposed to NDMA at 1 and $5 \mathrm{mg} / \mathrm{mL}(p<0.05)$

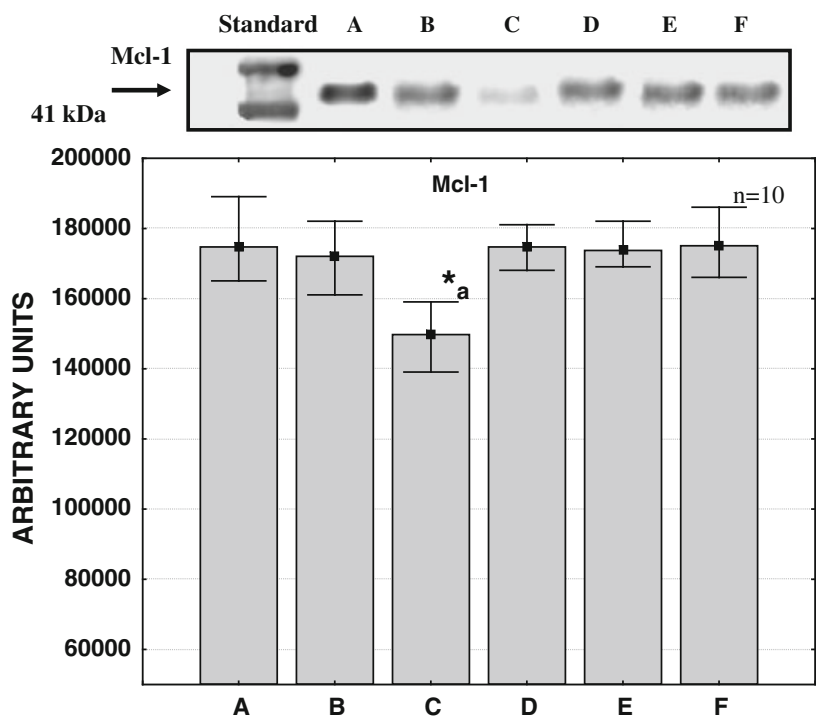

Fig. 2 Western blot analysis of Mcl-1 protein expression in human PMNs and PBMCs. A PMNs not exposed to NDMA (control), $B$ PMNs exposed to NDMA ( $1 \mathrm{mg} / \mathrm{mL}), C$ PMNs exposed to NDMA $(5 \mathrm{mg} / \mathrm{mL}), D$ PBMCs not exposed to NDMA (control), $E$ PBMCs exposed to NDMA (1 mg/mL), $F$ PBMCs exposed to NDMA (5 mg/ $\mathrm{mL}$ ). Each value represents the median $\pm \min / \max$, for $\mathrm{n}=10$.

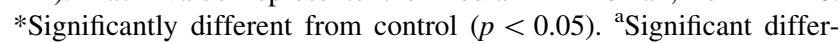
ence between cells exposed to NDMA at 1 and $5 \mathrm{mg} / \mathrm{mL}(p<0.05)$

present study decrease in cytochrome c concentrations in PMNs may indicate the release of this protein from mitochondria, and its binding to apoptotic protease-activating 
Table 1 Median \pm maximum and minimum values of apoptotic PMNs and PBMCs cells after isolation, after $20 \mathrm{~h}$ incubation without NDMA and with NDMA $(\mathrm{n}=10)$

\begin{tabular}{|c|c|c|c|c|c|c|}
\hline \multirow{2}{*}{$\begin{array}{l}\text { NDMA } \\
\text { concentration }\end{array}$} & \multicolumn{3}{|c|}{ PMNs (\% of apoptotic cells) } & \multicolumn{3}{|c|}{ PBMCs (\% of apoptotic cells) } \\
\hline & $\begin{array}{l}\text { After } \\
\text { isolation }\end{array}$ & $\begin{array}{l}\text { Not exposed to NDMA } \\
\text { after } 20 \mathrm{~h} \text { incubation }\end{array}$ & $\begin{array}{l}\text { Exposed to NDMA } \\
\text { after } 20 \mathrm{~h} \text { incubation }\end{array}$ & $\begin{array}{l}\text { After } \\
\text { isolation }\end{array}$ & $\begin{array}{l}\text { Not exposed to NDMA } \\
\text { after } 20 \mathrm{~h} \text { incubation }\end{array}$ & $\begin{array}{l}\text { Exposed to NDMA } \\
\text { after } 20 \mathrm{~h} \text { incubation }\end{array}$ \\
\hline $1 \mathrm{mg} / \mathrm{mL}$ & $\begin{array}{l}1.4 \pm 2.7 / \\
1.3\end{array}$ & $28.2 \pm 34.0 / 25.0$ & $32.2 \pm 36.1 / 26.2$ & $\begin{array}{l}0.7 \pm 1.3 / \\
0.6\end{array}$ & $7.3 \pm 10.0 / 5.9$ & $8.0 \pm 11.5 / 7.3$ \\
\hline $5 \mathrm{mg} / \mathrm{mL}$ & & & $41.6 \pm 47.0 / 33.1^{*}$ & & & $9.5 \pm 12.2 / 6.4$ \\
\hline
\end{tabular}

* Statistically difference between no exposed and exposed to $5 \mathrm{mg} / \mathrm{mL}$ NDMA cells $(p<0.05)$

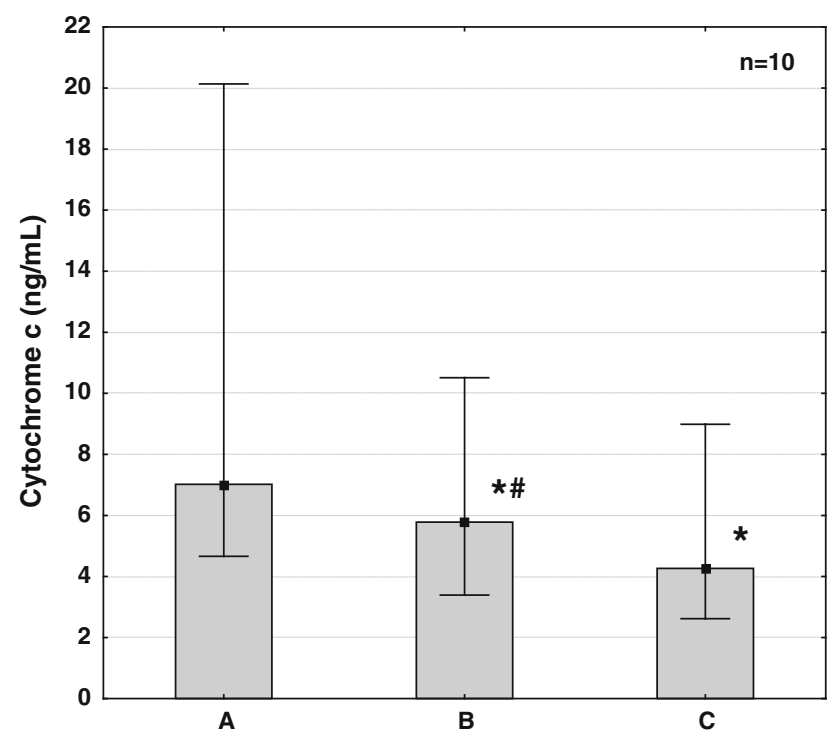

Fig. 3 Cytochrome c concentrations in the lysates of PMNs. A PMNs after isolation, $B$ PMNs not exposed to NDMA (control), $C$ PMNs exposed to NDMA $(5 \mathrm{mg} / \mathrm{mL})$. Each value represents the median \pm $\min / \max$, for $\mathrm{n}=10$. *Significantly different from cells after isolation $(p<0.05)$, \# significantly different from exposed to NDMA $(5 \mathrm{mg} / \mathrm{mL})(p<0.05)$

factor 1 (Apaf-1) (Fig. 3). Apaf-1 recruits procaspase-9, leading to activation of caspase-9. The active caspase 9 then efficiently activates other downstream caspases, bringing the morphological changes characteristic of apoptosis (Clohessy et al. 2006). Upregulation of Bax protein, observed in the current study, and earlier demonstrated increased expression of TRAIL-R2 (DR5) death receptor in human neutrophils together suggest an association between the Bcl-2 family of proteins and the TRAIL system in PMNs exposed to NDMA (Jablonski and Jablonska 2007).

Data presented by Deng et al. show that the Baxmediated mitochondrial pathway is required for TRAILinduced apoptosis in human cancer cells (Deng et al. 2002). Furthermore, Han et al. (2006) reported that the deficit of Bax in Hct116 cells had been shown to resist TRAILinduced apoptosis.
The link between death receptor signaling and the mitochondrial pathway apoptosis is associated with Bid cleaved by active caspase- 8 . The active part of the cleaved Bid translocates into mitochondria, binds Bax or Bak with resulting mitochondrial fragmentation and apoptogenic factor release, such as cytochrome c (Kumar et al. 2005). Furthermore, it was suggested that the Bax requirement for TRAIL-induced apoptosis was dependent on the mitochondrial release of Smac/DIABLO, which an important event mediated by Bax (Sprick and Walczak 2004).

Despite the effect of exogenous NDMA, the lifespan of PMNs may be also regulated by this compound in the autocrine pathway. Our earlier studies showed that PMNs can play a role in endogenous NDMA synthesis (Jablonski et al. 2006). The obtained results suggest that neutrophils through the release of NO may represent an important source of endogenous carcinogenic factors such as nitrosamines and peroxynitrite (Jablonski et al. 2006).

Similar data including alterations in the expression of anti-apoptotic proteins belonging to the $\mathrm{Bcl}-2$ family in the presence of xenobiotics were shown by Hatanaka et al. (2001), who observed a decrease of Bcl-x protein in rat liver after exposure to diethylnitrosamine (DEN). They even suggested that such a decrease of Bcl-x protein might serve as an indicator of the advanced form of preneoplastic lesions, which might also be associated with the potential to progress into a carcinoma.

In contrast to the PMNs, the autologous PBMCs exhibited no changes in the expression of either the Bax or Mcl-1 proteins, or in the intensity of the apoptosis. The differences above suggest that PMNs are more sensitive to NDMA exposure than PBMCs, which may be associated with the higher ability of PMNs to metabolize NDMA.

Summarizing, the results obtained revealed that the apoptosis process in human neutrophils exposed to NDMA is dependent not only on the extrinsic pathway mediated by the TRAIL/DR5 system, but also on the intrinsic pathway mediated by Bax and Mcl-1 proteins. Further extensive examinations, involving a larger number of proteins playing a role in the intrinsic and extrinsic pathway are required to fully understand the mechanism of NDMA influence on immune cells. 
Open Access This article is distributed under the terms of the Creative Commons Attribution Noncommercial License which permits any noncommercial use, distribution, and reproduction in any medium, provided the original author(s) and source are credited.

\section{References}

Akgul C, Dale A, Moulding S, Edwards W (2001) Molecular control of neutrophil apoptosis. FEBS Lett 487:318-322

Bøyum A (1976) Isolation of lymphocytes, granulocytes and macrophages. Scand J Immunol 5(suppl.):9-15

Clohessy JG, Zhuang J, de Boer J (2006) Mcl-1 interacts with truncated bid and inhibits its induction of cytochrome c release and its role in receptor-mediated apoptosis. J Biol Chem 281:5750-5759

Deng Y, Lin Y, Wu X (2002) TRAIL-induced apoptosis requires Baxdependent mitochondrial release of Smac/DIABLO. Genes Dev 16:33-45

Drela N (2006) Xenobiotic-induced alterations in thymocyte development. APMIS 114:399-419

Edwards SW, Derouet M, Howse M, Moots RJ (2004) Regulation of neutrophils apoptosis by Mcl-1. Biochem Soc Trans 32:489-492

Han J, Goldstein LA, Gatsman BR (2006) Interrelated roles for Mcl-1 and BIM in regulation of TRAIL-mediated mitochondrial apoptosis. J Biol Chem 281:10153-10163

Hatanaka Y, Nakae D, Mutai M, Hashizume K, Kamihara Y, Kinoshita N, Tani Y, Danno GG, Ohta S, Konishi Y, Ashida H (2001) Decreased expression of Bcl-x protein during hepatocarcinogenesis induced exogenously and endogenously in rats. Jpn J Cancer Res 92:1270-1277

Holsapple MP, Bick PH, Scherer S (1985) Effects of N-Nitrosodimethylamine on cell-mediated immunity. J Leukoc Biol 37: $367-381$

Jablonski J, Jablonska E (2007) The effect of $N$-nitrosodimethylamine on TRAIL and DR5 expression in human neutrophils-preliminary study. Immunopharmacol Immunotoxicol 29:287-296
Jablonski J, Jablonska E, Chojnowski M (2001) The influence of very low doses of $N$-nitrosodimethylamine (NDMA) on the apoptosis of rat neutrophils in vivo. The role of reactive oxygen species. Toxicology 165:65-74

Jablonski J, Jabłońska E, Moniuszko-Jakoniuk J (2003) The influence of $\mathrm{N}$-nitrosodimethylamine (NDMA) on the activity of antioxidant enzymes of neutrophil (PMN) of rats. In research in vivo. Acta Toxicol 11:21-26

Jablonski J, Jabłońska E, Iwanowska J, Marcinczyk M, MoniuszkoJakoniuk J (2006) The influence of human neutrophils on $\mathrm{N}$-nitrosodimethylamine (NDMA) synthesis. Immunopharmacol Immunotoxicol 28:93-102

Kumar R, Herbert PE, Warrens AN (2005) An introduction to death receptors in apoptosis. Int $\mathrm{J}$ Surg 3:268-277

Lee GH (1997) Correlation between Bcl-2 expression and histopathology in diethylnitrosamine-induced mouse hepatocellular tumors. Am J Pathol 151:957-961

Lee MW, Park SC, Yang YG, Yim SO, Chae HS, Bach JH, Lee HJ, Kim KY, Lee WB, Kim SS (2002) The involvment of reactive oxygen species (ROS) and p38-mitogen activated protein (MAP) kinase in TRAIL/Apo2L-induced apoptosis. FEBS Lett 512: 313-318

Lijinsky W (1999) $N$-nitroso compounds in the diet. Mutat Res Genet Toxicol Environ Mutagen 34:129-138

Renshaw SA, Parmar JS, Singleton V, Rowe SJ, Dockrell DH, Dower SK, Bingle CD, Chilvers ER, Whyte MKB (2003) Acceleration of human neutrophil apoptosis by TRAIL. J Immunol 170: $1027-1033$

Sharpe JC, Arnoult D, Youle RJ (2004) Control of mitochondrial permeability by Bcl2 family members. Biochim Biophys Acta 1644:107-113

Simon HU (2003) Neutrophil apoptosis pathways and their modifications in inflammation. Immunol Rev 193:101-110

Sprick MR, Walczak H (2004) The interplay between the Bcl-2 family and death receptor-mediated apoptosis. Biochim Biophys Acta 1644:125-132 